\title{
¿Qué es la Gran Historia?
}

\author{
David Christian \\ Universidad Macquarie \\ Traducido por Gabriel Gromadzyn
}

\begin{abstract}
La Gran Historia es un nuevo campo disciplinario de estudios que se ocupa del pasado en todas las escalas posibles. Su enfoque es histórico, pero vincula las disciplinas de la cosmología a la geología con la biología evolutiva y la historia humana. Comenzando “¿Qué es la Historia?” de E.H. Carr, este ensayo describe la evolución de la Gran Historia y, en particular, su relación con la disciplina histórica. Describe qué es la nueva disciplina y en qué podría convertirse. Sostiene que la Gran Historia puede ayudar a superar la fragmentación característica de la educación moderna y la erudición en todas las disciplinas. Al hacerlo, puede desentrañar algo así como una historia de origen moderna y global, basada en lo mejor de la erudición científica moderna.
\end{abstract}

Correspondence | David Christian, david.christian@mq.edu.au

Citation | Christian, D. (2018) ¿Qué es la Gran Historia? Journal of Big History, II(3); 139 - 156.

DOI | http://dx.doi.org/10.22339/jbh.v2i3.2340

Como se equivocan, quienes estudian los mapas de las regiones antes de haber aprendido con precisión la relación del universo entero y sus partes separadas y comparadas entre sí y con el todo, así como no están menos equivocados los que piensan que pueden entender historias particulares antes de tener un juicio de orden y secuencia de toda la historia universal y de todos los tiempos, expuesta por así decirlo en una tabla. ${ }^{1}$

La Gran Historia representa un intento de lo que E.O. Wilson ha llamado "Consiliencia", un retorno al objetivo de una comprensión unificada de la realidad, en lugar de las visiones fragmentadas que dominan la educación moderna y la erudición. ${ }^{2}$ Aunque parezca nuevo, el objetivo de la consiliencia es muy antiguo. E incluso en sus formas modernas, la Gran Historia ha existido por lo menos durante un cuarto de siglo. Por lo tanto, la publicación del primer número de The Journal of Big History ofrece la oportunidad ideal para realizar un inventario.

Este artículo es una cuenta personal en este campo. Ve a la Gran Historia como la forma moderna de un

1 Jean Bodin, siglo XVI, citado de Craig Benjamin "Beginnings and Endings", en Marnie Hughes-Warrington, ed., Palgrave Advances in World Histories, p. 95.

2 E.O. Wilson, Consilience: The Unity of Knowledge, Londres: Abacus, 1998. proyecto antiguo. Soy un historiador por formación, por lo que mi área de saber se centra en la relación de la Gran Historia con la disciplina de la historia. Refleja la perspectiva de un historiador entrenado en el mundo de habla inglesa, y se centra en la relación de la Gran Historia con la erudición histórica anglófona. Pero no sólo para la erudición histórica anglófona, porque los debates que discuto tenían sus contrapartidas y ecos en muchas otras tradiciones de erudición histórica. Tampoco me enfoco sólo en la erudición histórica como normalmente se entiende dentro de la academia, porque la Gran Historia ve la historia humana como parte de un pasado mucho más amplio que incluye el pasado estudiado por biólogos, paleontólogos, geólogos y cosmólogos. Al vincular diferentes perspectivas y escalas, y muchas disciplinas académicas diferentes, todas las cuales intentan comprender las raíces profundas del mundo de hoy, la Gran Historia puede transformar nuestra comprensión de la "historia".

Sin embargo, para capturar completamente la riqueza y el alcance de este nuevo y vibrante campo de investigación, erudición y enseñanza, eventualmente necesitaremos las perspectivas de grandes historiadores entrenados en muchas otras disciplinas. Espero que este ensayo pueda alentar a tales académicos a ofrecer sus perspectivas sobre la historia y la naturaleza de la Gran Historia. 


\section{La evolución de la erudición histórica en el siglo XX:}

Los historiadores reconocerán que mi título proviene de un ensayo clásico sobre historia, estudiado por la mayoría de los graduados de la historia de habla inglesa. Fue escrito en 1961 por E.H. Carr, un historiador de la Unión Soviética. El libro de Carr comenzó como una serie de conferencias dadas en Cambridge en 1961 en honor a George Macauley Trevelyan, un historiador que, a diferencia de Carr, consideraba que la disciplina de la historia era bastante distinta de las ciencias. Como historiador de Rusia y la Unión Soviética, Carr tomó en serio la insistencia marxista de que la historia debería ser considerada como una rama de la ciencia, y esa idea influyó en mi propio pensamiento sobre la historia ya que yo también ingresé al campo de la historia rusa como un graduado estudiante en la década de 1970.

En “¿Qué es la historia?”, Carr rastrea la evolución de la disciplina histórica en Inglaterra a principios del siglo XX. En un nivel, su historia es una tendencia sostenida que se aleja del realismo confiable, el positivismo e incluso el universalismo de muchos pensadores históricos del siglo XIX, hacia una creciente fragmentación y escepticismo. Él comienza citando la visión confiable de Lord Acton de la erudición histórica desde la década de 1890, cuando Acton presidió la primera edición de la Cambridge Modern History. Acton vio en ella "una oportunidad única de grabar, ... la plenitud del conocimiento que el siglo XIX está a punto de legar ...”. Agregó: "La última historia que no podemos tener en esta generación [pero] ... toda la información está ahora al alcance, y cada problema se ha convertido en una solución". ${ }^{3} \mathrm{La}$ visión de la historia de Acton es confiable, positivista y optimista, y asume que la historia es parte del proyecto más amplio de aumentar el conocimiento humano en general. Su visión de la historia también es amplia. Supuso que los historiadores deberían apuntar

3 E. H. Carr, ¿qué es historia? Penguin, 1964, 1er publicado en 1961, y entregado en 1961 como George Macaulay Trevelyan Lectures, Cambridge, 7. a algún tipo de "historia universal", aunque parece haber entendido que esa frase significa, no una forma temprana de Gran Historia, sino algo más cercano a la "historia mundial" o la "historia global" moderna. Acton definió la historia universal como "aquello que es distinto de la historia combinada de todos los países". 4

A principios del siglo $\mathrm{XX}$, la erudición histórica inglesa experimentó una profunda transformación, y cuando Carr escribió, la disciplina estaba más fracturada y menos segura de sí misma. Estos cambios fueron parte de un cambio radical que afectó a la mayoría de las disciplinas académicas, desde las humanidades hasta las ciencias naturales, ya que la especialización y la profesionalización dividieron a las becas en compartimentos cada vez más pequeños, cada uno ofreciendo su propia visión del mundo. La especialización demostró ser una poderosa estrategia de investigación, pero se logró cortando los antiguos vínculos entre los campos del conocimiento, dejándolos cada vez más aislados unos de otros. La idea de un sólo mundo de conocimiento, ya sea que esté unida por cosmologías religiosas como la cristiandad o la erudición científica, la visión que subyace al intento de Alexander von Humboldt de escribir una historia universal científica en su "Kosmos", fue abandonada. ${ }^{5}$ En disciplinas de humanidades como la historia, que carecían del tipo de ideas paradigmáticas unificadoras características de las ciencias naturales en la época de Darwin, de Maxwell y de Einstein, la especialización también socavó el realismo epistemológico confiable de Acton. ${ }^{6}$

Carr capta algunos de estos cambios al citar la introducción a la segunda edición de la Cambridge Modern History, escrita por George Clark en 1957,

4 Carr, ¿qué es historia? p. 150.

5 Sobre Humboldt como gran historiador antes de su tiempo, ver Fred Spier, Big History and the Future of Humanity, 2nd ed., Malden, Mass .: Wiley Blackwell, 2015, pp. 18-21, y Andrea Wulf, The Invention de la naturaleza: Las aventuras de Alexander von Humboldt, el héroe de la ciencia perdido, Londres: John Murray, 2015.

6 Carr, ¿qué es historia? p. 150. 
más de medio siglo después de las declaraciones de Acton. Después de citar las esperanzas de Acton de una "historia definitiva", Clark escribe:

\section{Los historiadores de una generación} posterior no esperan esa posibilidad. Esperan que su trabajo sea reemplazado una y otra vez. ... La exploración parece ser interminable, $\mathrm{y}$ algunos eruditos impacientes se refugian en el escepticismo, o al menos en la doctrina de que, dado que todos los juicios históricos involucran personas y puntos de vista, uno es tan bueno como otro y no hay una verdad histórica "objetiva". 7

La pérdida de confianza en una epistemología realista o naturalista en disciplinas como la historia, amplió el abismo entre las "dos culturas" de las ciencias y las humanidades que tanto preocupaban a C.P. Snow en una famosa conferencia pronunciada en $1959 .{ }^{8}$ El abismo era particularmente amplio en el mundo de habla inglesa, porque el inglés, a diferencia de la mayoría de los otros idiomas académicos, limitaba la palabra "ciencia" a las ciencias naturales. En inglés, la idea misma de "ciencia histórica" comenzó a parecer absurda. En la época de Carr, la erudición histórica había perdido la confianza tanto en la naturaleza "científica" de la erudición histórica, como en la epistemología realista que todavía apuntalaba la investigación en las ciencias naturales.

El escepticismo y la fragmentación intelectual socavaron la antigua esperanza de que la historia podría empoderarnos ayudándonos a comprender mejor el presente y debilitar la confianza en el valor de la investigación histórica. A medida que se aislaron cada vez más de otras disciplinas e incluso entre sí, los historiadores se quedaron con visiones cada vez más fragmentadas del pasado y de la naturaleza y los objetivos de la historia. Esta creciente sensación

\footnotetext{
7 Carr, ¿qué es historia? pag. 7-8.

8 C. P. Snow, Las dos culturas y la revolución cientifica (Cambridge, 1959).
}

de fragmentación fue la contraparte académica de lo que Durkheim llamó anomie, la pérdida de un sentido de coherencia y significado, una idea que Carr mismo resume en una nota al pie como "la condición del individuo aislado de ... la sociedad". 9 Académicamente, anomie surgió del aislamiento cada vez mayor de los académicos tanto unos de otros como de un mundo unificado de conocimiento. La única fuerza que mitigaba parcialmente la creciente sensación de aislamiento académico era el nacionalismo. Aunque tribal por su propia naturaleza, las historias nacionales, que habían florecido desde el siglo diecinueve, proporcionaron cierto sentido de cohesión para los historiadores que trabajan dentro de las tradiciones historiográficas nacionales.

La propia posición de Carr cae entre el realismo científico robusto de Acton y el relativismo vacilante de Clark. Él explora brillantemente la compleja dialéctica entre la historia como verdad, y la historia como historias que contamos sobre el pasado. Toma la verdad y la ciencia en serio, porque cree que la historia, como la ciencia, y como la verdad en general, tiene un propósito: puede empoderarnos. Nos fortalece al mejorar nuestra comprensión del presente, y lo realiza haciendo corresponder el presente con el pasado: "La función del historiador no es amar el pasado ni emanciparse del pasado, sino dominarlo y comprenderlo como la clave para la comprensión del presente " ${ }^{\prime \prime}$. De ello se desprende que los mapas del pasado creados por los historiadores deben ser buenos mapas. Como buena ciencia, tenían que darnos un mejor control del mundo real. Entonces Carr, como Marx, era un filósofo realista, y no vio un abismo fundamental entre las Humanidades y las Ciencias Naturales. ${ }^{10}$ "Científicos, científicos sociales e historiadores están involucrados en diferentes ramas del mismo estudio: el estudio del hombre y su entorno, de los efectos del hombre en su entorno y de su entorno en el hombre. El objeto del estudio es el mismo: aumentar la comprensión y el dominio del

9 Carr, ¿qué es historia? pag. 32.

10 Carr, ¿qué es historia? pag. 26. 
hombre sobre su entorno". ${ }^{11}$

Por otro lado, Carr entendió más claramente que Acton que el pasado no está simplemente esperando ser descubierto, "como pescado en el escaparate de una pescadería". ${ }^{12}$ La historia consiste en historias sobre el pasado construidas por historiadores, y cómo construimos esas historias, de como nuestro mundo y nuestros propósitos cambian. Necesitamos rigor empírico para llegar a la verdad sobre el pasado, pero cuando contamos historias sobre el pasado necesitaremos otras habilidades, incluyendo lo que Carr llama "comprensión imaginativa", la capacidad de comprender a quienes vivieron en el pasado. ${ }^{13}$ En esto, Carr fue influenciado por uno de los grandes filósofos ingleses de la historia, R. G. Collingwood, aunque advirtió que el énfasis de Collingwood en el papel activo del historiador, si se lo toma demasiado, podría llevar a un escepticismo extremo. ${ }^{14}$

Particularmente influyente en el pensamiento de Carr fue el equilibrio dialéctico de Marx entre la ciencia y el activismo. Marx insistió en que hay un pasado objetivo. Pero hacer que algo de ese pasado sea una tarea creativa, y cómo lo abordamos depende de quiénes somos y el presente particular en el que escribimos y estudiamos. Esta es la dialéctica que Marx describió en un famoso pasaje del " $18^{\text {avo }}$ Brumario de Luis Napoleón".

Los hombres hacen su propia historia, pero no la hacen como quieren; no lo hacen bajo circunstancias elegidas por ellos mismos, sino en circunstancias directamente encontradas, dadas y transmitidas desde el pasado. La tradición de todas las generaciones muertas pesa como una

11 Carr, ¿qué es historia? pag. 84.

12 Carr, ¿qué es historia? pag. 23.

13 Carr, ¿Qué es la historia? pag. 24.

14 El trabajo de Collingwood, al igual que el de Carr, era una opción básica para los graduados de mi generación. Su obra más importante fue R. G. Collingwood, The Idea of History, rev. ed., ed. Jan Van der Dussen (Oxford y Nueva York: Oxford University Press, 1994). pesadilla en el cerebro de los vivos. ${ }^{15}$

Los historiadores también "hacen su propia historia", pero lo hacen "bajo circunstancias directamente encontradas, dadas y transmitidas desde el pasado". Lo que hacen del pasado depende del tiempo y el lugar en el que escriben. Pero las historias que construyen sobre el pasado pueden, a su vez, influir en el pasado estudiado por los futuros historiadores. Como activista, Marx entendió bien que la forma en que describimos el pasado puede moldear el futuro.

Como Marx, Carr entendió el complejo y delicado equilibrio entre la historia como verdad y la historia como historia. La historia es, escribió Carr, en un pasaje familiar para muchos estudiantes de posgrado en historia: "un proceso contínuo de interacción entre el historiador y los hechos, un diálogo interminable entre el presente y el pasado". ${ }^{16}$ Al igual que la memoria, la historia no recuerda el pasado, lo vuelve a re-crear.

Pero, ¿qué pasado? Carr estaba aún más comprometido que Acton para ampliar el alcance de la investigación histórica. Después de todo, era un historiador de Rusia y estaba ansioso por demostrar la importancia de las historias que habían sido descuidadas por los historiadores de habla inglesa. Como admirador de Joseph Needham, también insistió en la importancia de la historia china y las historias de muchas otras partes del mundo más allá de Europa. Pero, aunque el pasado de Carr es amplio, no es profundo. Muestra poco interés en la prehistoria humana o en las historias de la biosfera y el universo. Y eso tal vez sea sorprendente, dado su interés por Marx, que veía la historia como parte de un conocimiento contínuo que incluía todas las ciencias. De hecho, Marx, como von Humboldt, fue un gran historiador anticipado a su tiempo. Pero Carr escribió en una era de fragmentación académica, y la Gran Historia no estaba en su radar, o en el radar de cualquier historiador de

15 Citado de Robert C. Tucker, ed., The Marx-Engels Reader, 2nd ed. (Nueva York y Londres: W.W. Norton \& Co., 1978), 595.

16 Carr, ¿qué es historia? pag. 30. 
lengua inglesa de su generación. Sin embargo, estaba en el radar de los historiadores de la Unión Soviética y China, cuya herencia marxista aseguró que la idea de la historia "universal" o "general" nunca perdiera por completo su sentido marxista inclusivo.

En 2001, David Cannadine editó una colección de ensayos llamada What is History Now? ¿Qué es la Historia ahora? basado en una conferencia celebrada para conmemorar el $40^{\mathrm{mo}}$ aniversario del libro de Carr. ${ }^{17}$ Mucho había cambiado desde que Carr escribió. En todo caso, la disciplina de la historia se había vuelto aún más fragmentada, tanto en contenido como en epistemología, y aún menos segura de sí misma. La visión universalista de Marx o von Humboldt o H.G. Wells, parecía haberse desvanecido por completo, sobreviviendo sólo en la versión reducida de las historias nacionales. Muchos de los cambios evidentes en la colección de Cannadine reflejan la proliferación de posguerra de universidades, estudiantes universitarios, historiadores y subdisciplinas históricas. Este fue un fenómeno mundial, por lo que las tendencias en la investigación histórica inglesa se pueden encontrar, con variaciones, en muchas tradiciones historiográficas diferentes.

El libro de Cannadine ya no se trataba de una sola disciplina de historia, por lo que era apropiado que tuviera múltiples autores. Más historiadores y más estudiantes parecían querer comunicar ideas cada vez más diversas sobre el contenido, el significado y el propósito de la erudición histórica. Cada capítulo trata sobre un tipo diferente de historia, por lo que hay capítulos llamados: “¿Qué es la historia social ahora?”, “¿Qué es la historia intelectual ahora?” Y “¿Qué es la historia cultural ahora?”. La ausencia de “¿Qué es la historia de las mujeres ahora?” O “¿Qué es la historia ambiental ahora?" sorprende, aunque Cannadine insiste en que su libro refleja sólo un pequeño número de subdisciplinas en las que se dividió la historia.

La fragmentación estuvo acompañada de un

17 David Cannadine, ed., ¿Qué es historia ahora? Basingstoke: Palgrave / Macmillan, 2002. creciente escepticismo sobre la objetividad y la naturaleza científica de la disciplina. Los historiadores se aislaron cada vez más incluso unos de otros, y cualquier consenso sobre la naturaleza y los objetivos de la historia parecía haberse evaporado. En un ensayo introductorio, Richard Evans señaló el creciente enfoque en la era posmodernista sobre el papel creativo y subjetivo del historiador y sobre el papel del historiador como narrador de historias. Este enfoque fue resumido en el clásico de Hayden White de 1973, Metahistory: The Imagination Historical in the 19th Century Europe, que se centró casi por completo en los aspectos literarios de la erudición histórica, en lugar de afirmaciones que de verdad hizo. Las investigaciones históricas parecen haberse dividido en historias múltiples e inconmensurables sobre el pasado, cada una representando una perspectiva particular, y ninguna confiada en sus afirmaciones sobre la verdad histórica. Los historiadores parecen haber asumido el profundo escepticismo hacia las grandes narrativas o metarrelatos que Jean-François Lyotard consideraba una característica definitoria del pensamiento posmoderno. ${ }^{18}$

$\mathrm{Y}$ sin embargo, ... aunque el cambio apenas se registró en los diales historiográficos del volumen de Cannadine, para el año 2000, la idea de una nueva forma de historia universal ya estaba sacudiendo las márgenes de la erudición histórica. La historia mundial estaba floreciendo en los Estados Unidos, tenía una organización académica bien establecida y una revista exitosa (The Journal of World History), y se enseñaba en un número cada vez mayor de universidades y escuelas. Pero varios estudiosos ahora se aventuraron mucho más allá de la historia mundial. Comenzaron a explorar la posibilidad de una historia verdaderamente universal que abarcaría todo el pasado, incluidos los pasados de la biosfera y el universo entero. Para 2001, había enseñado la Gran Historia durante 12 años, pero sólo era un miembro de una pequeña pero vigorosa

18 Jean-François Lyotard, La condición posmoderna: un informe sobre el conocimiento, transl. Geoff Bennington y Brian Massumi (Minneapolis: Universidad de Minnesota Press, 1984). 
comunidad de académicos que se movían en la misma dirección. Eric Chaisson había estado enseñando versiones astronómicas de la Gran Historia durante más de veinte años, y la Gran Historia se enseñaba en Amsterdam por Fred Spier y Joop Goudsblom, en Dallas por John Mears, en San Francisco por Cynthia Stokes-Brown, en Melbourne por Tom Griffiths y Graeme Davidson, y en otros lugares. La Gran Historia se coló como disciplina histórica que miraba en la dirección opuesta.

Hoy, quince años después del volumen de Cannadine, la Gran Historia sigue siendo marginal, pero está comenzando a sacudir la disciplina de la historia. ${ }^{19}$ Existe una literatura académica emergente que demuestra que la Gran Historia puede escribirse con rigor y precisión, y puede producir nuevos conocimientos transformadores sobre el pasado. ${ }^{20}$ La Gran Historia se enseña con éxito en varias universidades, principalmente en el mundo de habla inglesa, e incluso los departamentos de historia que no la enseñan a menudo incluyen discusiones sobre la Gran Historia en sus seminarios de historiografía. Hay una asociación académica (la IBHA), y ahora una revista de Gran Historia. Gran Historia incluso se enseña en muchas escuelas secundarias, a través del

19 Un ejemplo interesante es The History Manifesto, de Jo Guldi y David Armitage, Cambridge: CUP, 2014, que ofrece una crítica agresiva del cortoplacismo en la literatura histórica contemporánea.

20 A start up list might include Eric Chaisson, Cosmic Evolution: The Rise of Complexity in Nature, Cambridge, MA: Harvard University Press, 2001; David Christian, Maps of Time: An Introduction to Big History, Berkeley, CA: University of California Press, 2nd ed., 2011; Fred Spier, Big History and the Future of Humanity, 2nd ed., Malden, MA: Wiley/Blackwell, 2015; Cynthia Stokes Brown, Big History: From the Big Bang to the Present, 2nd ed., New York: New Press, 2012; a university text, David Christian, Cynthia Stokes Brown, and Craig Benjamin, Big History: Between Nothing and Everything, New York: McGraw-Hill, 2014; anthologies of essays, such as Barry Rodrique, Leonid Grinin and Andrey Korotayev, eds., From Big Bang to Galactic Civilizations: A Big History Anthology, Vol. 1, Our Place in the Univere, Delhi: Primus Books, 2015; and a beautifully illustrated overview, Macquarie University Big History Institute, Big History, London: DK books, 2016.
"Big History Project", un plan de estudios gratuito en línea lanzado en 2011 y financiado por Bill Gates.

Lo que parecía sólo décadas atrás, un enfoque arcaico, irreal y perverso de la erudición histórica ahora está comenzando a parecer una forma poderosa, rigurosa e incluso transformadora de la erudición moderna, que puede volver a conectar la erudición histórica y la enseñanza una vez más a otras disciplinas tanto en Humanidades como las otras Ciencias.

\section{¿Por qué el regreso a la Historia Universal? ¿Qué pasó?}

Algunos de los cambios cruciales ocurrieron dentro de la disciplina histórica. Siempre hubo algunos académicos, como H.G. Wells o Arnold Toynbee, que mantuvieron viva la visión de una comprensión más amplia del pasado. Pero la investigación especializada también sentó las bases para una visión más amplia del pasado, generando una cantidad colosal de nueva erudición histórica, y abordando temas y regiones y épocas que habían sido ignoradas por generaciones anteriores de historiadores. Felipe FernándezArmesto, un historiador mundial con intereses extraordinariamente amplios, lo describe muy bien en un capítulo del volumen de Cannadine:

"los historiadores cavan surcos cada vez más profundos en un suelo cada vez más seco hasta que los surcos colapsan y quedan sepultados bajo su propia aridez". Sin embargo, por otro lado, cada vez que uno sale del surco, ahora hay mucho más campo que estudiar, tanto trabajo nuevo y enriquecedor, que puede cambiar la perspectiva o ampliar el marco de comparación ". 21

Pero muchos de los cambios que permitieron el retorno a la historia universal ocurrieron más allá de la disciplina histórica, y particularmente dentro de las ciencias naturales, que siempre habían sido más amistosas que las humanidades a la idea de la

21 Cannadine, ed., ¿Qué es historia ahora? pag. 149. 
consiliencia. ${ }^{22}$ El físico cuántico, Erwin Schrodinger, ya había anticipado nuevas formas de unificación académica en un libro que escribió justo después de la Segunda Guerra Mundial sobre la naturaleza de la vida.

Hemos heredado de nuestros antepasados el profundo anhelo de un conocimiento unificado y universal. El mismo nombre dado a las más altas instituciones de aprendizaje nos recuerda que, desde la antigüedad y durante muchos siglos, el aspecto universal ha sido el único al que se le ha dado todo el crédito. ... Sentimos claramente que recién ahora estamos empezando a adquirir material confiable para soldar juntos la suma total de todo lo que se conoce en un todo; ... ${ }^{23}$

En las ciencias naturales, como en las humanidades, la erudición especializada durante muchas décadas produjo una gran cantidad de nueva información e ideas. Igualmente importante fue la aparición de nuevas ideas paradigmáticas unificadoras. Los más importantes fueron la cosmología del big bang, la tectónica de las placas y la síntesis darwiniana moderna. Los nuevos paradigmas apenas eran visibles cuando Carr escribió. El ADN había sido descubierto en la propia Universidad de Cambridge, en 1953, pero el significado completo del descubrimiento volvería sólo en la próxima década o dos. Los descubrimientos que afianzaron la tectónica de placas y la cosmología del big bang aún se encontraban en el futuro. Para 1970, sin embargo, los nuevos paradigmas ya alentaban las esperanzas de una nueva unificación del conocimiento, al menos en las ciencias naturales. Algunos científicos incluso comenzaron a hablar de "Grandes Teorías Unificadas".

22 Esta sección resume y agrega argumentos que presenté en "El retorno de la historia universal".

23 Erwin Schrödinger, ¿Qué es la vida? CUP, 2000, p. 1 [primer publ. 1944]; Schrodinger también era muy consciente de las barreras que la especialización ponía en el camino de tales ambiciones.
Particularmente llamativo es el hecho de que los nuevos paradigmas científicos eran de naturaleza histórica. Se había ido el universo estático de Newton, reemplazado por un universo que operaba de acuerdo con las reglas históricas y evolutivas. E.H. Carr era consciente del "giro histórico" en las ciencias naturales, y su significado para la historia, aunque sus ideas serían ignoradas por la mayoría de los historiadores durante los próximos cincuenta años más o menos. La revista Science escribió:

"había experimentado una profunda revolución ... Lo que Lyell hizo por la geología y Darwin por la biología, se ha hecho ahora para la astronomía, que se ha convertido en una ciencia de cómo el universo llegó a ser lo que es ... El historiador tiene alguna excusa para sentirse más a gusto en el mundo de la ciencia de lo que podría haberse sentido hace cien años." 24

La cosmología del big bang alentó a astrónomos como Carl Sagan a contar la historia del universo, mientras que la tectónica de placas alentó a geólogos como Preston Cloud a escribir nuevas historias del planeta tierra. ${ }^{25}$ Resultó que muchos científicos naturales estaban en el mismo negocio sucio que los historiadores, esto es, intentar reconstruir un pasado desaparecido desde pistas aleatorias. El giro histórico en las ciencias naturales acercó los métodos de los científicos a los de los historiadores. Los experimentos controlados sobre los orígenes de la vida en la Tierra o la Revolución Rusa estaban fuera de discusión. En cambio, resultó que muchas disciplinas científicas enfrentaban el mismo desafío metodológico que los historiadores: recolectar tantas pistas del pasado como pudieran, desde la antigua luz de las estrellas hasta los cristales de circonio y los trilobites fósiles, y usarlos para reconstruir plausibles relatos del pasado. Este era un territorio familiar para los historiadores.

24 Carr, ¿Qué es historia? pag. 57.

25 La serie de televisión de Carl Sagan, Cosmos, se emitió por primera vez en 1980; Cosmos, tierra y hombre de Preston Cloud: Una breve historia del universo, New Haven: Yale University Press, se publicó justo dos años antes, en 1978. 
Las desaprobaciones preferidas de Karl Popper rara vez estaban disponibles, y otras habilidades, más borrosas, tales como el reconocimiento de patrones o las corazonadas basadas en la familiaridad prolongada con un campo dado, adquirieron una relevancia creciente tanto en las ciencias naturales como en las humanidades. ${ }^{26}$

De particular importancia para la aparición de las formas modernas de la historia universal fue el desarrollo de técnicas de datación radiométrica que podría proporcionar un esqueleto cronológico firme para las historias del pasado lejano. ${ }^{27}$ Cuando H.G. Wells intentó una historia universal justo después de la Primera Guerra Mundial, las primeras partes de su historia se debilitaron porque, como Wells admitió, todas sus fechas absolutas dependían de los registros escritos, por lo que no pudo proporcionar ninguna antes de la Primera Olimpiada (776 A.C.). ${ }^{28}$ Los geólogos del siglo XIX habían aprendido cómo construir cronologías relativas mediante el estudio de la estratificación de rocas antiguas, pero nadie podía decir cuándo ocurrió la explosión del Cámbrico o cuándo se formó la Tierra.

Todo esto cambió con la aparición de las técnicas de datación radiométrica en la década de 1950. En 1953, Claire Paterson utilizó la vida media del uranio en meteoritos para determinar que la Tierra tenía 4.560 millones de años. Su fecha se mantiene hasta el día de hoy. Cuando Carr escribió en 1961, la datación radiométrica apenas comenzaba a transformar el pensamiento de los arqueólogos y prehistoriadores. En 1962, en la cueva Kenniff en S. Queensland,

26 Hay una buena descripción de las metodologías reales, en oposición a las idealizadas, de la ciencia moderna en John Ziman, Real Science: Qué es y qué significa. CUP, 2000.

27 Véase David Christian, "Historia, complejidad y revolución cronométrica", Revista de Occidente, abril de 2008, No 323, 27-57, y David Christian, "Historia y ciencia después del Revolución cronométrica “, en Steven J. Dick y Mark L. Lupisella, eds., Cosmos \& Culture: Evolución cultural en un contexto cósmico, NASA, 2009, pp. 441-462.

28 H.G. Wells, Outline of History: Being a Plain History of Life and Mankind, 3rd ed., (New York: Macmillan), 1921, 1102.
John Mulvaney utilizó técnicas radiométricas para demostrar que los humanos habían vivido en Australia desde antes de la última edad de hielo, y en sus próximas décadas, como las primeras fechas para el asentamiento humano en Australia lo que sería correr la fecha entre 50.000 y quizás 60.000 años. ${ }^{29}$ Como escribe Colin Renfrew:

... el desarrollo de métodos de datación radiométrica, ... permitió la construcción de una cronología para la prehistoria en cada parte del mundo. Era, además, una cronología libre de suposiciones sobre desarrollos culturales o relaciones, y podría aplicarse tanto a sociedades sin literatura como a aquellos con registros escritos. Ser prehistórico ya no significa ser ahistórico en un sentido cronológico. ${ }^{30}$

Eventualmente, las técnicas radiométricas y otras técnicas de datación permitieron construir cronologías rigurosas que se remontaban a los orígenes del universo. Por primera vez, ahora es posible contar una historia universal basada en una cronología universal robusta.

Algunos de estos cambios simplemente se registraron en la colección de ensayos de David Cannadine. En el último capítulo de ese libro, Felipe Fernández-Armesto argumentó que la historia había ampliado su ámbito de aplicación, especialización por especialización, y ahora es necesario abrazar las ciencias naturales: "la historia ya no puede permanecer en uno de los campamentos de las 'dos culturas'. Los seres humanos son obviamente parte de la herencia animal"31 En 1998, el gran historiador mundial, William H. McNeill, argumentó que los historiadores necesitaban integrar la historia de la humanidad dentro de la historia de la biosfera e incluso del universo como un todo:

29 John Mulvaney y Johan Kamminga, Prehistoria de Australia, Sydney: Allen y Unwin, 1999, 1-2.

30 Colin Renfrew, Prehistoria: La fabricación de la mente humana, Londres: Weidenfeld y Nicolson, 2007, 41.

31 Cannadine, ¿qué es historia ahora? pag. 153. 
Aparentemente, los seres humanos pertenecen al universo y comparten su carácter inestable y de evolución. ...lo que sucede entre los seres humanos y lo que sucede entre las estrellas parece ser parte de una historia grande, que evoluciona con aparición espontánea de complejidad que genera nuevos tipos de comportamiento en todos los niveles de organización desde los quarks y leptones más diminutos hasta las galaxias, desde las largas cadenas de carbono hasta los organismos vivos $\mathrm{y}$ la biosfera, y desde la biosfera hasta los universos simbólicos de significado dentro del cual los seres humanos viven y trabajan, ... 32

En sus últimos años, McNeill se interesó cada vez más en la idea de la Gran Historia, viéndola como una extensión natural de su propia visión amplia de la historia. Fue, como su hijo, John, quien escribió: "lo que más le emocionó (aparte de mis nietos)". ${ }^{33}$

\section{¿Qué es Big History?}

\section{Entonces, ¿qué es la Gran Historia?}

En la parte final de este ensayo me gustaría explorar varias descripciones superpuestas de lo que es la Gran Historia y lo que podría ser. Estos son pensamientos personales, y algunos son especulativos. Pero espero que les pueda interesar incluso a aquellos que están menos persuadidos que yo. $\mathrm{Y}$ espero que puedan alentar una amplia discusión sobre la Gran Historia y su futuro. Mis pensamientos están organizados, vagamente, a lo largo de un espectro que va desde el final de la "verdad" de la dialéctica de la historia de Carr hacia el final de la "narración de historias".

\section{El objetivo de la Gran Historia, como la de todo} buen conocimiento, es capacitarnos ayudándonos

32 William H. McNeill, "Historia y la cosmovisión científica", History and Theory, 37, no. 1 (1998): 12-13.

33 Orígenes: Boletín de la Asociación Internacional de Big History, 2016, VI.08, p. 7. a comprender el mundo en el que vivimos. La Gran Historia nos fortalece al ayudarnos a comprender nuestro mundo. Al igual que todas las formas de la historia, la Gran Historia nos empodera principalmente mediante el mapeo del presente en el pasado, a fin de ayudarnos a comprender mejor cómo el mundo de hoy llegó a ser como es. Esta afirmación sobre el propósito de la historia supone una comprensión realista o naturalista del conocimiento. Como criaturas evolucionadas, interactuamos con nuestro entorno con cierto grado de éxito, y ese éxito presupone que nosotros (como todos los organismos vivos) podemos lograr una comprensión limitada pero real de nuestro entorno. Aunque consciente de los límites del conocimiento, la Gran Historia, como la ciencia en general, resiste formas extremas de escepticismo o relativismo. Se basa en los mismos fundamentos realistas y naturalistas que las buenas ciencias, y tiene el mismo objetivo final de empoderamiento.

La Gran Historia es universal. Pero si entender el pasado puede empoderarnos, ¿no deberíamos tratar de comprender todo el pasado? Lo que distingue a la Gran Historia más decisivamente de otras formas de estudios históricos, es su intento de comprender el pasado como un todo. Aspira a una comprensión universal de la historia. La Gran Historia no es hostil a áreas históricas especializadas. Por el contrario, es completamente dependiente de los ricos materiales generados por los especialistas. Pero trata de vincular los hallazgos de especialistas en una visión más amplia y unificadora, de la misma forma en que se pueden conectar millones de mapas locales para formar un mapa mundial único. Estos ambiciosos objetivos significan que la Gran Historia nada contra la marea de fragmentación intelectual que tanta literatura erigió en el siglo XX. La Gran Historia apunta a la consiliencia, a lo que Alexander von Humboldt una vez llamó el "frenesí loco ... de representar en una sola obra todo el mundo material". ${ }^{4}$

34 Andrew Wulf, La invención de la naturaleza: Las aventuras de Alexander von Humboldt, el héroe perdido de la ciencia, Londres: John Murray, 2015. 
Muchas consecuencias interesantes fluyen del ambicioso universalismo de la Gran Historia. Ella no reconoce barreras disciplinarias al conocimiento histórico. Supone la existencia de toda una gama de disciplinas orientadas históricamente, todas vinculadas por el mismo proyecto: el de reconstruir cómo nuestro mundo llegó a ser tal como es. De hecho, a menudo me pregunto si no veremos, en algún momento en el futuro, una reorganización de los campus universitarios, de modo que, en lugar de poner las ciencias en un extremo y las humanidades en el otro, se pueda encontrar una zona dedicada a "las ciencias históricas", en las que puedes encontrar a astrónomos, geólogos, biólogos evolutivos, neurocientíficos e historiadores trabajando juntos.

Las aspiraciones universales de la Gran Historia significan que abarcará todas las áreas de conocimiento que han generado explicaciones plausibles, rigurosas y basadas en la evidencia del pasado, y cualquier disciplina cuyos conocimientos puedan iluminar el pasado. Esto significa que, en este momento, tiene sentido trazar una línea entre todo lo que sucedió justo después del big bang -un pasado que puede reconstruirse con montones de evidencias- y todo lo que precedió al big bang, territorio donde hay muchas cosas interesantes en cuanto a especulación, pero hasta el momento se trata de una historia tensa, no basada en la evidencia. Esto puede cambiar, por supuesto, en cuyo caso, la historia de la Gran Historia misma se expandirá para incorporar, tal vez, evidencia de un multiverso o de la teoría de cuerdas. Cambios similares pueden ocurrir en otras partes de la historia de la Gran Historia, mientras los biólogos exploran los orígenes de la vida en la Tierra o los astrónomos buscan vida alrededor de otros sistemas estelares, o cuando los neurocientíficos y psicólogos comienzan a controlar lo 'duro' en el tema de la conciencia.

Con estas calificaciones, la Gran Historia apunta a una comprensión integral de la historia, el equivalente intelectual de un mapa del mundo del pasado. Al igual que un mapa del mundo, la Gran Historia puede ayudarnos a ver no sólo las principales naciones y océanos delpasado, sino también los vínculos y sinergias que conectan diferentes continentes académicos, regiones e islas en un único mundo del conocimiento. La amplia perspectiva de la Gran Historia también nos alienta a movernos entre múltiples escalas, desde las del universo mismo, a las de los humanos, a las de las células individuales, dentro de las cuales millones de reacciones precisamente calibradas ocurren cada segundo. La Gran Historia nos anima a conectar los puntos en el tiempo y el espacio, para buscar las sinergias que vinculan entidades, disciplinas y escalas dispares.

Al centrarse en las redes de ideas que vinculan las disciplinas, la Gran Historia puede ayudarnos a superar las formas más extremas del característico escepticismo de gran parte de la erudición del siglo XX, particularmente en humanidades. En manos de Durkheim, la idea de "anomia" se refería a la ausencia de un sentido claro de lugar o significado, una condición de falta de marco intelectual en el que el mundo mismo tenía poco sentido y los individuos podían sentirse lo suficientemente aislados como para contemplar el suicidio. La extrema fragmentación de la erudición del siglo XX permitió un gran progreso intelectual, disciplina por disciplina. Pero lo hizo a costa de aislar las disciplinas entre sí, y eso limitó las posibilidades tanto para una visión más amplia y unificadora como para la verificación de la verdad entre las disciplinas. Particularmente en las humanidades, el aislamiento intelectual generó formas académicas de anomia que minaban la confianza en cualquier reclamo para generar significado o para lograr una comprensión provisional de la realidad. El escepticismo posmoderno compartido por tantos eruditos en humanidades a finales del siglo XX fue un correctivo útil para las formas de positivismo demasiado confiadas en si mismas. Pero, cuando se lleva a los extremos, creó un sentido fragmentado de la realidad que podría ser profundamente desautorizador, tanto intelectual como éticamente.

La Gran Historia vuelve, con la debida modestia científica, al antiguo proyecto de intentar ensamblar 
mapas unificados de la realidad. Al romper las divisiones entre disciplinas, la Gran Historia puede ayudar a restablecer una relación más equilibrada entre la erudición especializada y las grandes ideas paradigmáticas.

La Gran Historia es colaborativa y colectiva. La Gran Historia está siendo ensamblada, como un vasto mosaico, utilizando fichas de diferentes países, épocas y disciplinas académicas. Toda su área es colaborativa. Pero el extraordinario rango de la Gran Historia pone a la colaboración en el corazón de la nueva disciplina. Una buena historia de la Gran Historia no será el producto de mentes eruditas individuales, sino la creación conjunta de miles, quizás millones, de mentes diferentes.

La colaboración académica extrema requerida para escribir una Gran Historia debería alentar una reconsideración de lo que queremos decir con experiencia. La especialización alentó la idea de que, si se reducía el campo de investigación lo suficiente, los académicos individuales podrían lograr el dominio total de un campo. Se convirtieron en expertos. Este punto de vista siempre fue ingenuo porque incluso el mejor de los expertos recurrió a percepciones y paradigmas fuera de sus campos de experiencia. Pero la amplitud extraordinaria de la Gran Historia significa que, si bien se basará en las percepciones de los expertos, también requerirá muchas otras habilidades académicas, no todas las cuales se valoran en el mundo fragmentado del conocimiento actual. La Gran Historia requiere, sobre todo, una habilidad para comprender y luego vincular la erudición de muchos estudiosos de diferentes disciplinas. Exige amplitud tanto como profundidad. Requiere un ojo agudo para sinergias inesperadas entre disciplinas. Y requiere la capacidad de sintonizar las diferentes frecuencias intelectuales de múltiples disciplinas. Los grandes historiadores tendrán que ser traductores interdisciplinarios, sensibles a los matices sutiles en la forma en que las diferentes disciplinas usan conceptos, palabras y métodos similares. Y también harán preguntas profundas interdisciplinarias. ¿Puede la idea de entropía, que juega un papel tan poderoso en la física, iluminar nuestra comprensión de la historia humana? ¿Pueden las máquinas moleculares de nivel atómico que exploran hoy los nanobiólogos sugerir nuevas formas de gestionar los flujos de energía en el mundo actual ${ }^{33}$ ¿Existen mecanismos universales (quizás alguna forma de darwinismo universal) que expliquen la aparición de entidades cada vez más complejas a pesar de la segunda ley de la termodinámica? ${ }^{35}$

Al centrarse no sólo en los órganos individuales de la erudición moderna, sino también en los tejidos que los conectan, la Gran Historia puede proporcionar un nuevo tipo de marco para el pensamiento e investigación interdisciplinarios. Los investigadores que estén familiarizados con el mapa del pasado de la Gran Historia natural buscarán naturalmente ideas y métodos útiles que van más allá de sus propias disciplinas especializadas. La investigación transdisciplinaria cobrará especial importancia a medida que más y más problemas, desde el cambio climático hasta el estudio del cáncer o las crisis financieras, comiencen a depender no de la investigación dentro de una sola disciplina, sino de la combinación de hallazgos y conocimientos de múltiples disciplinas. De hecho, el éxito mismo de la investigación dentro de las disciplinas explica por qué ahora hay cada vez más problemas interesantes e importantes entre las disciplinas. A medida que la investigación interdisciplinaria se vuelve cada vez más importante, la Gran Historia puede ofrecer un nuevo modelo de buena investigación, que se centre en la amplitud del conocimiento y un buen ojo para las sinergias interdisciplinarias inesperadas.

\section{La joven disciplina de la Gran Historia también}

35 Peter Hoffmann, Life's Ratchet, es una exploración maravillosa de cómo las máquinas moleculares explotan la "tormenta molecular" creada por la energía aleatoria de las moléculas individuales para impulsar la química de las células; y por qué hacerlo no infringe la segunda ley de la termodinámica porque depende de fuentes adicionales de energía libre, principalmente suministradas por la molécula de la batería, el ATP. 
ha demostrado que la colaboración intelectual es una característica distintiva de nuestra especie, homo sapiens. Aunque muchas características evolutivas nos definen como una especie, nuestra creatividad tecnológica parece haber sido asegurada por la evolución de una forma de lenguaje particularmente poderosa, que nos permite intercambiar ideas y percepciones con tanta precisión y en tal volumen que comienzan a acumularse en la memoria colectiva. No conocemos otras especies en las que el conocimiento aprendido se acumule a través de múltiples generaciones para que las generaciones posteriores conozcan, no sólo cosas diferentes, sino más cosas que las generaciones anteriores. Y esta diferencia ha demostrado ser transformadora. El intercambio de información aprendida entre millones de personas en múltiples generaciones explica nuestro creciente control sobre los recursos y los flujos de energía de la biosfera. Esta tendencia sostenida ha formado gran parte de la historia humana, y ha culminado hoy en hacernos la fuerza más poderosa para el cambio en la biosfera. En mi propio trabajo, describí esta capacidad para compartir y acumular información como "aprendizaje colectivo". Nos ha dado a los humanos no sólo un mayor control sobre los flujos de energía y recursos a través del medio ambiente, sino también una mayor comprensión del mundo y el universo que habitamos. La ciencia moderna, así como las religiones y literaturas modernas, son todas creaciones de millones de individuos que trabajan en redes de conocimiento compartidas.

Mi convicción personal es que la idea de "aprendizaje colectivo" ofrece una idea paradigmática que puede enmarcar nuestra comprensión de la historia humana y de la naturaleza distintiva de nuestra propia especie. La historia humana está impulsada por el aprendizaje colectivo, del mismo modo que la historia de los organismos vivientes está impulsada por la selección natural. Si esta idea es ampliamente correcta, ilustra la capacidad de la Gran Historia para aclarar problemas profundos al ayudarnos a verlos en un contexto excepcionalmente amplio, como parte del "mapa mundial" del conocimiento moderno. ${ }^{36}$

La Gran Historia es una historia. Hasta ahora, he discutido la naturaleza de las afirmaciones de verdad que pueden hacerse a partir de la Gran Historia y su capacidad para sinergizar la investigación colaborativa e interdisciplinaria. Pero, por supuesto, la Gran Historia también cuenta una historia. Surge, como Carr escribió de toda la historia, de "un diálogo interminable entre el presente y el pasado". Sus dos polos son el pasado como un todo, y los historiadores que ven ese pasado desde un punto de vista particular en el presente. Como la historia en general, la Gran Historia es en gran medida un producto de los historiadores que están construyendo la Gran Historia. Eso significa, por supuesto, que la Gran Historia está evolucionando y evolucionando, como todas las historias, según lo cuentan los diferentes escrutadores, escribiendo en diferentes contextos y con diferentes preocupaciones.

La Gran Historia es una historia de origen. Pero debido a sus ambiciones universalistas, la Gran Historia no es sólo otra historia sobre el pasado. Sus ambiciones universales significan que la Gran Historia comparte mucho con las historias de origen tradicionales. Hasta donde sabemos, todas las comunidades humanas han tratado de construir informes unificados de los orígenes de todo lo que nos rodea. Este es el sentido en el que usaré la idea de "historias de origen". Las historias de origen intentan mantenerse unidas y transmiten todo lo que se conoce en una comunidad determinada sobre cómo nuestro mundo llegó a ser como es. Son extraordinariamente poderosos si se les cree, si suenan fieles a los que los escuchan y los repiten, si estamos hablando de comunidades agrícolas del mundo paleolítico, o las grandes tradiciones filosóficas y religiosas de las principales civilizaciones mundiales, desde el confucionismo hasta el budismo, pasando por las tradiciones del mundo azteca, del cristianismo y el islam. También son poderosos porque son

36 On the idea of a Noösphere, see David Christian, "The Noösphere," (January 2017) on https://www.edge.org/, 2017 Annual Question 
compartidas por la mayoría de los miembros de una comunidad determinada, que aprenden los rudimentos de sus historias de origen cuando eran niños, y luego internalizan esas historias en el transcurso de muchos años de educación, con mayor detalle y sofisticación. Hasta donde sabemos, las historias de origen se pueden encontrar en el centro de todas las formas de educación. Han proporcionado conocimiento fundamental en seminarios y universidades, y también en las ricas tradiciones orales transmitidas por los ancianos en todas las comunidades agrícolas.

A la luz de esta discusión, es evidente que la noción de "anomia" de Durkheim también puede entenderse como el estado de ánimo de quienes carecen de acceso a una historia de origen creíble, rica y autorizada. La anomia intelectual es un estado de ausencia de mapas y sin sentido. Curiosamente, es el estado intelectual el que se convirtió en la norma en el siglo XX, ya que la globalización y la ciencia moderna maltrataron la confianza en las historias de origen tradicional, tanto en los centros metropolitanos del mundo como en sus márgenes coloniales. En todas partes, los sistemas educativos seculares modernos dejaron de enseñar dentro de tradiciones compartidas de conocimiento fundacional.

Algunos encontraron la decadencia de las historias de origen tradicional estimulantes y liberadoras, y se glorificaron en las perspectivas múltiples y flotantes de un mundo sin una historia de origen compartida. Pero muchos, tanto en el mundo colonial como en el corazón metropolitano, experimentaron y continúan experimentando un profundo sentimiento de pérdida. Hoy estamos tan acostumbrados a un mundo sin ideas universales (particularmente en Humanidades), que es fácil olvidar lo doloroso que es perder el sentido de coherencia intelectual que acompaña a la confianza en una historia de origen. Pero la sensación de pérdida es evidente en gran parte de la literatura, la filosofía y el arte de finales del siglo XIX y principios del siglo XX. Aquí hay sólo dos ejemplos, más o menos aleatorios, de lo que quiero decir. En su poema de 1851, "Dover Beach", Matthew Arnold escribe:
El Mar de la Fe

Estaba una vez, también, envolviendo toda la orilla de la tierra

Como acostada en los pliegues de una faja brillante enrollada.

Pero ahora sólo escucho

Su melancólico, largo y abrupto rugido

Retirándose, a la respiración

Del viento nocturno, por los vastos bordes

Y las tejas desnudas del mundo.

El poema continúa con una aterradora visión de un futuro dislocado:

Ah, amor, seamos reales

¡el uno al otro! para el mundo, que parece

Para mentirnos como una tierra de sueños,

Tan variados, tan hermosos, tan nuevos,

Realmente no tiene alegría, ni amor, ni luz,

Ni certeza, ni paz, ni ayuda para el dolor;

Y estamos aquí como en una llanura oscura

Barrido con alarmas confusas de lucha y vuelo,

Donde los ejércitos ignorantes se enfrentan por la noche.

"La segunda venida" de W.B. Yeats fue escrita en 1919, justo después de que la Primera Guerra y pareciera ilustrar la inquietante visión del futuro de Arnold.

Girando y girando en el giro ensanchado

El halcón no puede oír al cetrero;

Las cosas se desmoronan; el centro no puede sostenerse;

La mera anarquía se desata sobre el mundo,

La marea atenuada por la sangre se desata y en todas partes

La ceremonia de la inocencia está ahogada; 
El poema termina con una imagen inquietante $\mathrm{y}$ aterradora:

Qué áspera bestia, su hora llegó por fin, ¿Te arrastras hacia Belén para nacer?

La especialización y la pérdida de las narrativas unificadoras tradicionales eran sintomáticas del mundo caótico e incoherente descrito en tanta literatura, arte y filosofía del siglo XX. De hecho, a menudo se ha supuesto que este mundo de disciplinas y perspectivas aisladas, incluso inconmensurables, es característico de la modernidad en general. El mundo moderno armó pueblos, culturas, religiones y tradiciones de manera tan violenta que creó una creciente sensación de humanidad única, al mismo tiempo que socavaba la confianza en las visiones unificadoras tradicionales del mundo. En el Manifiesto Comunista, leemos que, en la era burguesa de la historia humana: "Todas las relaciones fijas, congeladas rápidamente, con su tren de antiguos y venerables prejuicios y opiniones, son barridas, todas las formas nuevas se vuelven anticuadas antes de que ellas puedan osificarse. Todo lo que es sólido se derrite en el aire, todo lo que es santo es profanado ... ". En un libro sobre modernidad que toma su título de este pasaje, Marshall Berman escribe que el mundo moderno ha creado: "una unidad paradójica, una unidad de desunión; nos arroja a todos en una vorágine de perpetua desintegración y renovación, de lucha y contradicción, de ambigüedad $\mathrm{y}$ angustia. Ser moderno es ser parte de un universo en el que, como dijo Marx: 'todo lo sólido se derrite en el aire"".37

Pero una interpretación diferente también es posible. Tal vez durante gran parte del siglo $\mathrm{XX}$, hemos vivido en una especie de sitio de construcción intelectual, rodeado por los restos de historias de origen más antiguas, mientras que una nueva historia de origen se estaba construyendo a nuestro alrededor, una historia para la humanidad en general. La mejor evidencia para esta idea es la reaparición de historias

37 Marshall Berman, Todo lo que es sólido se funde en el aire: la experiencia de la modernidad, Nueva York: Penguin, 1988 [1 ${ }^{\circ}$ publicado en 1982$]$, p. 15. unificadoras en los últimos cincuenta años. Visto desde esta perspectiva, la Gran Historia es el proyecto para de tratar de desentrañar y construir una historia de origen moderna y global.

\section{La Gran Historia es una historia de origen para}

la Era del Antropoceno. Tal vez, entonces, podamos pensar en la Gran Historia como una historia de origen para el mundo muy extraño del siglo XXI. La Gran Historia se basa en los logros intelectuales de la ciencia moderna en el siglo XX, pero también es el producto de un mundo globalizado. Este es un mundo radicalmente diferente al de E.H. Carr. El conocimiento científico ha avanzado más rápido de lo que podría haber imaginado, y las nuevas tecnologías como internet han creado un mundo mucho más entrelazado que el que él conocía. Pero quizás los cambios más importantes surgen de la gran aceleración, el asombroso aumento en el número de humanos, el uso de energía humana, el control humano sobre el medio ambiente y la interconexión humana, en los sesenta años transcurridos desde la publicación de Carr. En ese breve período, los seres humanos nos hemos convertido colectivamente en la fuerza individual más importante para el cambio en la biosfera, la primera especie única que desempeña ese papel en la historia de la vida en 4 mil millones de años en la Tierra. Ese es un resultado que Carr no pudo haber imaginado en 1961. Estos cambios espectaculares significan que las preguntas sobre la naturaleza y la fuente del asombroso poder ejercido colectivamente por 7 mil millones de seres humanos son mucho más grandes que en la época de Carr. En este sentido, la Gran Historia puede considerarse como una historia de origen para la Era Antropocénica de la historia humana.

Necesitaremos la gran escala de la Gran Historia para ver al Antropoceno claramente, porque no es sólo un punto de inflexión en la historia mundial moderna, sino un umbral significativo dentro de la historia humana en su conjunto, e incluso en la historia de la biosfera. La mayoría de las investigaciones históricas contemporáneas estudia los últimos 500 años. El peligro de esta perspectiva es que puede normalizar la historia reciente, haciendo que las 
sociedades tecnológicas y económicamente dinámicas de los últimos siglos parezcan típicas de la historia humana en general. Pero no lo son. Su dinamismo es extraordinario y excepcional. La idea misma de historia, de cambio a largo plazo, es moderna y, como lo ha demostrado John McNeill, la escala del cambio en la era moderna, y particularmente desde mediados del siglo XX, es realmente "algo nuevo bajo el sol". ${ }^{38}$ Por el contrario, la mayoría de las personas en la mayoría de las sociedades humanas en los últimos 200,000 años vivieron vidas cuyas estructuras y sus alrededores parecían relativamente estables, porque el cambio fue tan lento que no se pudo observar en la escala de unas pocas generaciones.

Sólo dentro de las amplias escalas de la Gran Historia es posible ver claramente que la Era del Antropoceno es extraña no sólo en las escalas humanas, sino también en las de la historia del planeta tierra. Esta es quizás la razón por la cual, en un artículo reciente, un grupo de paleontólogos sugiere que la Era del Antropoceno cuenta como uno de los tres cambios más importantes en la historia de la biosfera, junto con la aparición de la vida, hace casi 4.000 millones de años, y la vida multicelular hace 600 millones de años. ${ }^{39}$ Nunca antes una sola especie ha dominado el cambio en la biosfera, como lo hacemos los humanos hoy en día, y nunca antes ha dependido el futuro cercano como lo hace hoy, en las decisiones, percepciones y caprichos de una sola especie. Apreciar la extrañeza de la sociedad moderna es vital si queremos entenderlo lo suficientemente bien como para enfrentar los desafíos globales que plantea para el futuro cercano. Comprender qué tan extraño es el mundo de hoy también puede darnos una apreciación renovada de los conocimientos y la comprensión de nuestros antepasados, que mantuvieron a lo largo de muchos milenios una relación mucho más estable que las sociedades modernas con la biosfera en su

38 Para más información sobre estas afirmaciones, ver David Christian, "History and Time", Australian Journal of Politics and History, Volumen 57, Número 3, 2011, pp. 353-365, y John McNeill, Something New under the Sun.

39 Mark Williams, Jan Zalasiewicz, et. al., "The Anthropocene Biosphere", The Anthropocene Review. DOI: 10.1177/2053019615591020, 2015, 1-24. conjunto.

La Gran Historia es la primera historia de origen para todos los humanos. Si la Gran Historia es una historia de origen, también es la primera historia de origen para la humanidad en general. Emergiendo como lo hace en un mundo profundamente interconectado, es la primera historia de origen construida por, y disponible para todos los seres humanos. Si bien las historias de origen tradicionales intentaron resumir el conocimiento de comunidades o regiones particulares o tradiciones culturales, esta es la primera historia de origen que intenta resumir el conocimiento acumulado de todas partes del mundo. Sólo eso sugiere la riqueza de la información y la asombrosa riqueza de detalles de una historia de origen moderna.

Las historias de origen tradicional proporcionaban una visión unificadora para comunidades particulares, destacando las ideas que compartían las diferentes personas, así como las historias nacionales modernas proporcionaban una visión unificadora para los estados nacionales a pesar de las diferencias internas de idioma, cultura, religión y etnia. De manera similar, la Gran Historia puede comenzar a proporcionar una visión unificadora para la humanidad como un todo, a pesar de las muchas diferencias entre regiones, naciones y tradiciones culturales. La construcción y diseminación de una historia de origen global puede ayudar a generar el sentido de unidad humana que se necesitará a medida que las sociedades humanas naveguen colectivamente a través de los desafíos globales de las próximas décadas. Aunque los tribalismos nacionales y culturales que dominaron el mundo de Carr todavía están muy presentes hoy en día, se habría sorprendido de ver, surgiendo junto a ellos, una historia de origen para la humanidad en su conjunto.

Tan interconectado es el mundo de hoy que la idea de una humanidad unificada con una historia propia, tiene una relevancia que carecía en la época de Carr, cuando las comunidades humanas más significativas parecían ser estados nacionales o regiones culturalmente cohesivas, como "Occidente" o el mundo musulmán, o las zonas dominadas por 
grandes imperios tradicionales como China o la India. Hoy, un sentido de ciudadanía global, de pertenencia a la comunidad global de la humanidad, no es sólo una cuestión de precisión científica. (Genéricamente hablando, somos, después de todo, una especie notablemente homogénea, de modo que la categoría homo sapiens tiene una precisión científica que carece de la categoría de "ser humano chino" o "ser humano estadounidense"). La conciencia de lo que comparten todos los humanos cada vez más, es una cuestión de autopreservación, particularmente en un mundo con armas nucleares. E.H. Carr escribió "¿Qué es la historia?" Un año antes de la crisis de los misiles en Cuba, cuando, según el presidente Kennedy, las probabilidades de una guerra nuclear total eran "uno de cada tres". ${ }^{40}$

El intento de H. G. Wells de escribir una historia universal en 1919, cuando los horrores de la Primera Gran Guerra aún vivían en su mente, fue impulsado por una fuerza similar. La paz, argumentó, requería nuevas formas de pensar. Requería ideas históricas comunes. Sin tales ideas para mantenerse juntos en una cooperación armoniosa, frente a tradiciones nacionalistas estrechas, egoístas y conflictivas, las razas y los pueblos están destinados a derivar al conflicto y la destrucción. Esta verdad, que fue evidente para ese gran filósofo Kant hace un siglo o más. . ahora es claro para el hombre en la calle. ${ }^{41}$

Más recientemente, el gran historiador estadounidense mundial, William McNeill, ha destacado con igual elocuencia:

La humanidad en su conjunto posee una característica común que los historiadores pueden esperar comprender tan firmemente cuando puedan comprender lo que une a cualquier grupo menor. En lugar de intensificar los conflictos, como lo hace inevitablemente la historiografía local,

40 Zelikow, P. y Graham Allison. 1999. Essence of Decision: Explaining the Missile Crisis, 2nd ed., Longman, p. 271.

41 Wells, H.G. 1991. Esquema de la Historia, 3.a ed., 1921, vi. cabe esperar que una historia mundial inteligible disminuya la letalidad de los encuentros grupales cultivando un sentido de identificación individual con los triunfos y las tribulaciones de la humanidad en su conjunto. Esto, de hecho, me parece el deber moral de la profesión histórica en nuestro tiempo. Necesitamos desarrollar una historia ecuménica, con mucho espacio para la diversidad humana en toda su complejidad. ${ }^{42}$

Como Wells entendió, una historia universal es el vehículo natural para una historia unificada de la humanidad, porque, a diferencia de las historias nacionales, la Gran Historia primero encuentra a los humanos no como tribus enfrentadas, sino como una sola especie. Y es una historia que ahora, con creciente precisión y confianza, puede ayudarnos a comprender el lugar de nuestra especie no sólo en el pasado reciente, sino en la historia de la biosfera y del universo entero.

42 William H. McNeill, "Mythistory, o Verdad, mito, historia e historiadores", The American Historical Review, vol. 91, No. 1, (febrero de 1986), pp. 1-10, p. 7. 


\section{Notas al Final}

1. Jean Bodin, siglo XVI, citado de Craig Benjamin "Beginnings and Endings", en Marnie HughesWarrington, ed., Palgrave Advances in World Histories, p. 95

2. E.O. Wilson, Consilience: The Unity of Knowledge, Londres: Abacus, 1998

3. Carr, ¿qué es historia? Penguin, 1964, 1er publicado en 1961, y entregado en 1961 como George Macaulay Trevelyan Lectures, Cambridge, 7

4. Carr, ¿qué es historia? P. 150

5. Sobre Humboldt como gran historiador antes de su tiempo, ver Fred Spier, Big History and the Future of Humanity, 2nd ed., Malden, Mass .: Wiley Blackwell, 2015, pp. 18-21, y Andrea Wulf, The Invention de la naturaleza: Las aventuras de Alexander von Humboldt, el héroe de la ciencia perdido, Londres: John Murray, 2015.

6. La distinción entre paradigma y disciplinas previas al paradigma fue introducida por un libro cuya primera edición apareció en 1962, solo un año después del libro de Carr: Thomas Kuhn, The Structure of Scientific Revolutions, 2nd ed., Chicago: University of Chicago Press 1970

7. Carr, ¿qué es historia? pag. 7-8

8. C. P. Snow, Las dos culturas y la revolución cientifica (Cambridge, 1959)

9. Carr, ¿qué es historia? pag. 32

10. Carr, ¿qué es historia? pag. 26

11. Carr, ¿qué es historia? pag. 84

12. Carr, ¿qué es historia? pag. 23

13. Carr, ¿Qué es la historia? pag. 24

14. El trabajo de Collingwood, al igual que el de Carr, era una opción básica para los graduados de mi generación. Su obra más importante fue R. G. Collingwood, The Idea of History, rev. ed., ed. Jan Van der Dussen (Oxford y Nueva York: Oxford University Press, 1994)

15. citado de Robert C. Tucker, ed., The Marx-Engels Reader, 2nd ed. (Nueva York y Londres: W.W. Norton \& Co., 1978), 595
16. Carr, ¿qué es historia? pag. 30

17. David Cannadine, ed., ¿Qué es historia ahora? Basingstoke: Palgrave / Macmillan, 2002

18. Jean-François Lyotard, La condición posmoderna: un informe sobre el conocimiento, transl. Geoff Bennington y Brian Massumi (Minneapolis: Universidad de Minnesota Press, 1984)

19. Un ejemplo interesante es The History Manifesto, de Jo Guldi y David Armitage, Cambridge: CUP, 2014, que ofrece una crítica agresiva del cortoplacismo en la literatura histórica contemporánea.

20. Cannadine, ed., ¿Qué es historia ahora? pag. 149

21. Esta sección resume y agrega argumentos que presenté en "El retorno de la historia universal".

22. Erwin Schrödinger, ¿Qué es la vida? CUP, 2000, p. 1 [primer publ. 1944]; Schrodinger también era muy consciente de las barreras que la especialización ponía en el camino de tales ambiciones

23. Carr, ¿Qué es historia? pag. 57

24. La serie de televisión de Carl Sagan, Cosmos, se emitió por primera vez en 1980; Cosmos, tierra y hombre de Preston Cloud: una breve historia del universo, New Haven: Yale University Press, se publicó justo dos años antes, en 1978

25. Hay una buena descripción de las metodologías reales, en oposición a las idealizadas, de la ciencia moderna en John Ziman, Real Science: Qué es y qué significa. CUP, 2000

26. Véase David Christian, "Historia, complejidad y revolución cronométrica", Revista de Occidente, abril de 2008, No 323, 27-57, y David Christian, "Historia y ciencia después del Revolución cronométrica ", en Steven J. Dick y Mark L. Lupisella, eds., Cosmos \& Culture: Evolución cultural en un contexto cósmico, NASA, 2009, pp. 441-462

27. John Mulvaney y Johan Kamminga, Prehistoria de Australia, Sydney: Allen y Unwin, 1999, 1-2

28. Colin Renfrew, Prehistoria: La fabricación de la mente humana, Londres: Weidenfeld y Nicolson, 
2007, 41

29. Cannadine, ¿qué es historia ahora? pag. 153

30. William H. McNeill, "Historia y la cosmovisión científica", History and Theory, 37, no. 1 (1998): 12-13

31. Orígenes: Boletín de la Asociación Internacional de Big History, 2016, VI.08, p. 7

32. Andrew Wulf, La invención de la naturaleza: Las aventuras de Alexander von Humboldt, el héroe perdido de la ciencia, Londres: John Murray, 2015, p.

33. Peter Hoffmann, Life 's Ratchet, es una exploración maravillosa de cómo las máquinas moleculares explotan la "tormenta molecular" creada por la energía aleatoria de las moléculas individuales para impulsar la química de las células; y por qué hacerlo no infringe la segunda ley de la termodinámica porque depende de fuentes adicionales de energía libre, principalmente suministradas por la molécula de la batería, el ATP.

34. Marshall Berman, Todo lo que es sólido se funde en el aire: la experiencia de la modernidad, Nueva York: Penguin, 1988 [ $1^{\circ}$ publicado en 1982], p. 15

35. Para más información sobre estas afirmaciones, ver David Christian, "History and Time", Australian Journal of Politics and History, Volumen 57, Número 3, 2011, pp. 353-365, y John McNeill, Something New under the Sun,

36. Mark Williams, Jan Zalasiewicz, et. al., "The Anthropocene Biosphere", 2015, 1-24

37. Zelikow, P. y Graham Allison. 1999. Essence of Decision: Explaining the Missile Crisis, 2nd ed., Longman, p.271

38. Wells, H.G. 1991. Esquema de la Historia, 3.a ed., 1921, vi

39. William H. McNeill, "Mythistory, o Verdad, mito, historia e historiadores", The American Historical Review, vol. 91, No. 1, (febrero de 1986), pp. 1-10, p. 7 